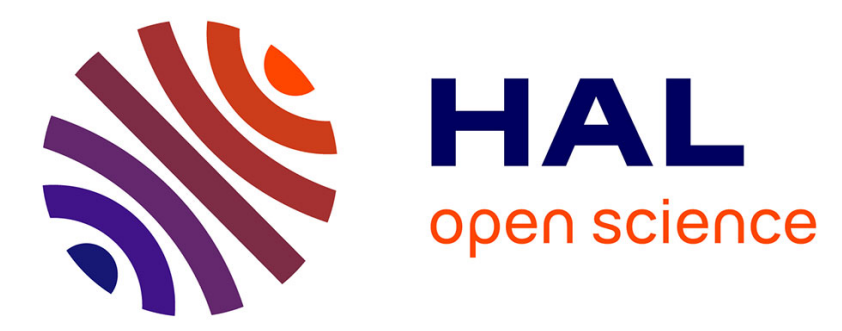

\title{
3-D computer vision in experimental mechanics
}

Jean-José Orteu

\section{To cite this version:}

Jean-José Orteu. 3-D computer vision in experimental mechanics. Optics and Lasers in Engineering, 2009, 47 (3-4, SI), p.282-291. 10.1016/j.optlaseng.2007.11.009 . hal-01644891

\section{HAL Id: hal-01644891 \\ https://hal.science/hal-01644891}

Submitted on 19 Feb 2018

HAL is a multi-disciplinary open access archive for the deposit and dissemination of scientific research documents, whether they are published or not. The documents may come from teaching and research institutions in France or abroad, or from public or private research centers.
L'archive ouverte pluridisciplinaire HAL, est destinée au dépôt et à la diffusion de documents scientifiques de niveau recherche, publiés ou non, émanant des établissements d'enseignement et de recherche français ou étrangers, des laboratoires publics ou privés. 


\title{
3-D computer vision in experimental mechanics
}

\author{
Jean-José Orteu* \\ Ecole Mines Albi, Campus Jarlard, 81013 Albi, France
}

\begin{abstract}
Optical methods that give displacement or strain fields are now widely used in experimental mechanics. Some of the methods can only measure in plane displacements/strains on planar specimens and some of them can give both in plane and out of plane displacement/ strain fields on any kind of specimen (planar or not). In the present paper, the stereovision technique that uses two cameras to measure $3 \mathrm{D}$ displacement/strain fields on any $3 \mathrm{D}$ object is presented. Additionally, a quite inclusive list of references on applications of stereovision (and 3 D DIC) to experimental mechanics is given at the end of the paper.
\end{abstract}

Keywords: Stereovision; Stereo-correlation; 3-D digital image correlation (3D-DIC); Shape measurement; Displacement/strain measurement; Experimental mechanics

\section{Introduction}

Full-field optical techniques for displacement or strain measurements are now widely used in experimental mechanics. The main techniques are photoelasticity, geometric moiré, moiré interferometry, holographic interferometry, speckle interferometry (ESPI), the grid method and digital image correlation (DIC) [1-9]. It should be noted that some of these techniques can only measure inplane displacements/strains on planar specimens and some of them can give both in-plane and out-of-plane displacement/strain fields on any kind of specimen (planar or not). Due to its (apparent) simplicity and versatility, the DIC method is probably one of the most commonly used methods, and many applications can be found in the literature $^{1}[10-45]$. When it is used with a single camera (classical DIC), the DIC method can only give in-plane displacement/strain fields on planar objects. By using two cameras (stereovision), the 3-D displacement field and the

\footnotetext{
*Tel.: + 33563493073 ; fax: + 33563493099 .

E-mail address: Jean-Jose.Orteu@enstimac.fr

URL: http://www.enstimac.fr/

${ }^{1}$ To date, the author has noted more than 350 journal papers dealing with DIC-based measurements in experimental mechanics. The reference list can be provided upon request.
}

surface strain field of any 3-D object can be measured. Using stereovision in conjunction with DIC leads to a socalled digital image stereo-correlation technique (DISC), also called 3-D DIC. In this paper, the stereovision (and 3-D DIC) technique developed at the Research Center on Tools, Materials and Forming Processes (CROMeP) at École des Mines d'Albi is presented.

\section{Stereovision for 3-D shape and 3-D displacement/strain measurement}

Binocular stereovision is a technique for recovering the 3-D structure of a scene from two different viewpoints (see Fig. 1 where $P(X, Y, Z)$ is the 3 -D point to be measured, $p_{1}\left(u_{1}, v_{1}\right)$ and $p_{2}\left(u_{2}, v_{2}\right)$ are its stereo projections in the images, $C_{1}$ and $C_{2}$ are the optical centers of the two cameras).

From a pair of images, it is possible to compute the 3-D coordinates of a physical 3-D point by triangulation assuming that:

1. The geometry of the stereo rig (i.e. the relative position and orientation of the two cameras) is known. This problem is solved by an off-line camera calibration procedure. 


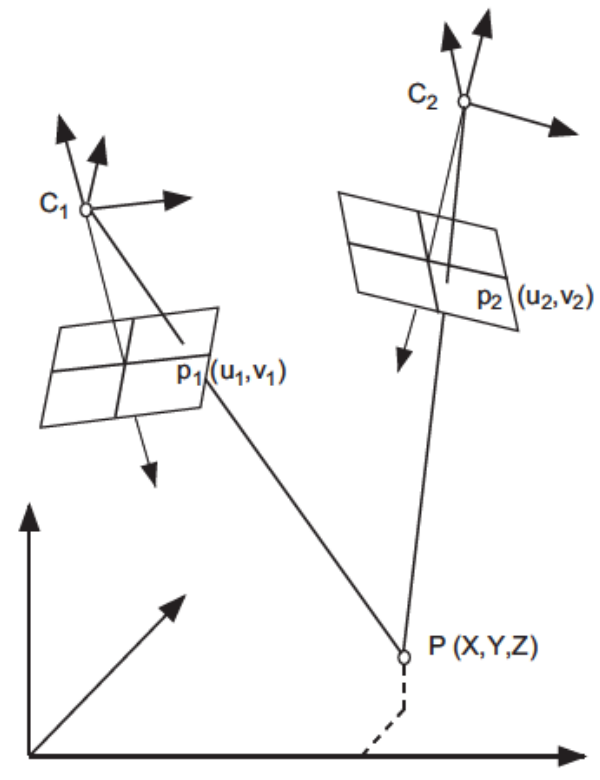

Fig. 1. Binocular stereovision.

2. The two image points $p_{1}$ and $p_{2}$ are matched, i.e. identified as corresponding to the same physical point $P$. This is called the stereo-matching problem.

\subsection{Calibration of the stereovision sensor}

Camera calibration is an important task in 3-D computer vision, particularly when metric data are required for applications involving accurate dimensional measurements.

Calibrating a camera involves determining its intrinsic parameters (generally, the two coordinates in the image frame of the intersection of the optical axis with the image plane, the two scale factors along the vertical and horizontal axes of the image frame, and, if need be, the lens distortion parameters) and its position and orientation with respect to an arbitrary world reference frame [46]. Calibrating a stereovision sensor made up of two cameras involves determining the intrinsic parameters of each camera and the relative position and orientation between the two cameras (see Fig. 2). These calibration data are required to compute, by triangulation, the 3-D coordinates of a point corresponding to matched pixels on the two images.

An original and flexible technique has been developed to easily calibrate a camera or a stereovision sensor. Lens distortion is taken into account. The technique only requires the camera to observe a (planar) pattern shown at a few different orientations (typically between 10 and 20). The motion of the pattern need not be known and the pattern itself can be imprecise (i.e. its geometry need not be known accurately). Using a photogrammetric bundle adjustment approach [47], the intrinsic parameters of each camera (including the distortion parameters), the 3-D points of the pattern and the relative position and

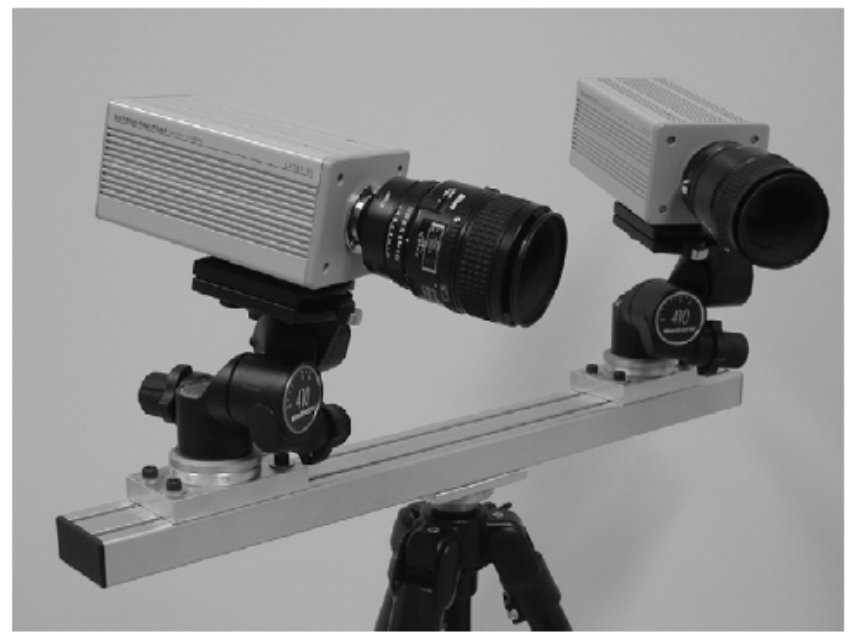

Fig. 2. The stereo rig used in our lab.

orientation between the two cameras are estimated all together. The technique is easy to use, flexible and leads to a highly accurate calibration $[48,49]$.

The calibration parameters will be used throughout this paper at different stages for:

- the rectification of the pairs of stereo images;

- the correction of lens distortion;

- the calculation of the 3-D position of a scene point from its stereo projections by triangulation.

\subsection{Rectification of the pair of stereo images}

Given a point $p_{1}$ in image 1 , its corresponding point $p_{2}$ in image 2, called stereo-correspondant (this is the stereomatching problem discussed in Section 2.3) appears to be always lying along a line of image 2 entirely defined by the coordinates of $p_{1}$, the relative position/orientation of the two cameras and their intrinsic parameters: this is the socalled epipolar line associated to $p_{1}[50,51]$ (see Fig. 3). This geometric constraint inherent to any stereo imaging system, called the epipolar constraint, is very interesting since it simplifies the search for the stereo-correspondant of a given point from a 2-D search across the entire image to a 1-D search along its epipolar line.

In the particular case where the cameras are perfectly aligned, the epipolar lines are parallel to the image rows (see Fig. 4): this ideal configuration simplifies the search for correspondence since corresponding pixels are on the same row in both images. In this configuration, the difference between the column coordinates of two matched points is called "disparity".

In practice, the mechanical alignment of the cameras is very difficult to obtain. Nevertheless, the problem can be solved at the processing level by applying a transformation (plane-to-plane homography ${ }^{2}$ ) to each image of the initial

\footnotetext{
${ }^{2} \mathrm{~A}$ plane-to-plane homography is a bijective projective transformation mapping pairs of points between planes [51,52].
} 


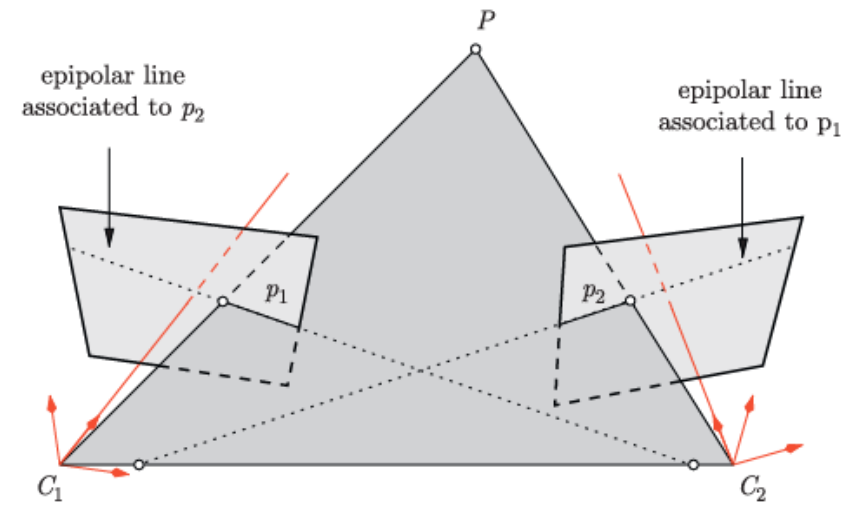

Fig. 3. The camera optical centers $C_{1}$ and $C_{2}$, the 3-D point $P$ and its images $p_{1}$ and $p_{2}$ lie in a common plane. This plane intersects each image plane in an epipolar line.

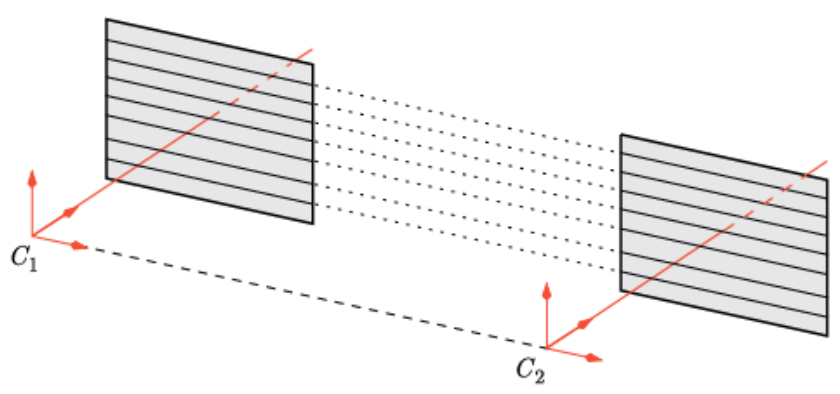

Fig. 4. A rectified stereovision sensor: the epipolar lines are parallel to the image rows.

stereo pair to obtain a new pair of stereo images corresponding to a virtual stereo rig with perfectly aligned cameras [50,51]. This rectification procedure uses the calibration parameters computed in the off-line camera calibration phase. Notice that during the rectification, the real distorted images (due to optical lens distortion) are also transformed into ideal distortion-free images.

The image rectification procedure results in a pair of images that corresponds to an ideal stereo rig of distortion free and perfectly aligned cameras. This greatly simplifies the stereo-matching phase.

It should be noted that, in practice, neither the rectified images nor the undistorted images are computed. In fact, the computed rectification homographies and the distortion parameters are used directly in the expression of the correlation function to work on the raw images. This new approach can achieve the highest matching accuracy by avoiding the pixel interpolations involved in the distortion correction and rectification of the images (see [49,53] for more details).

\subsection{Stereo-matching}

The main difficulty in stereovision is to establish correspondences between pairs of images. Over the years, numerous algorithms for image matching have been proposed. They can be classified into two categories:

1. Feature matching: The algorithms first extract salient primitives from the images, such as edge segments or contours, and match them in the views being considered. These methods are fast because only a small subset of the image pixels is used but usually give few matches (sparse disparity maps).

2. Template matching: The algorithms attempt to correlate the grey levels of image patches in the views being considered, assuming that they present some similarity. The underlying assumption appears to be a valid one for relatively textured areas and for image pairs with small differences. These methods can give dense disparity maps.

In [54], a method based on stereovision for measuring strains in stamped 3-D sheet metal parts was proposed. This method falls into category 1 as it requires that a predefined pattern (a grid of squares) be applied to the sheet surface before stamping. Each image of the stereo pair is processed independently in order to locate the grid intersections. The grid intersections are extracted in such a way as to allow an automatic matching between the two images, provided that the operator matches manually a single pair of points.

A stereo-correlation technique that falls into category 2 has also been developed (and is presented below). With this technique, a regular grid need not be applied to the object and the meshes used to compute the local strains are generated at the post-processing level (meshes of any size can be generated, and in particular small ones to take into account the large strain gradients).

Correlation scores are computed by measuring the similarity of a fixed window in the first image to a shifting window in the second (see Fig. 5). The second window is moved into the second image by integer increments along the corresponding image row (remember that a "rectified space" is being worked with) and a curve of correlation scores is generated (see Fig. 6). The correct matching corresponds to the highest peak provided that this peak is greater than a threshold $\left(S_{\min }\right)$. Note that a match is not accepted if the highest and the second highest peaks are

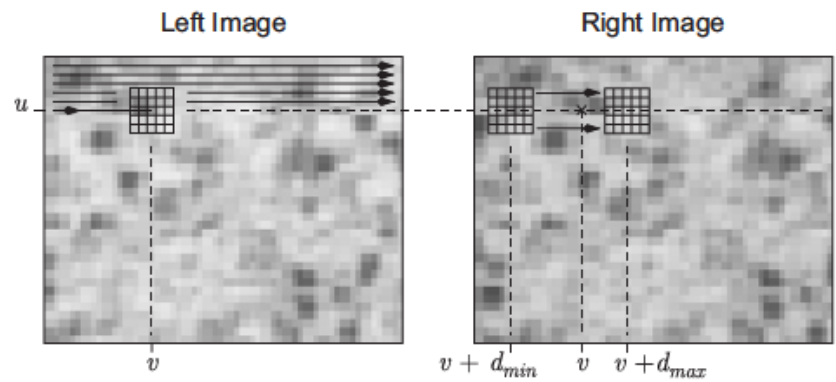

Fig. 5. Correlation-based stereo-matching. 


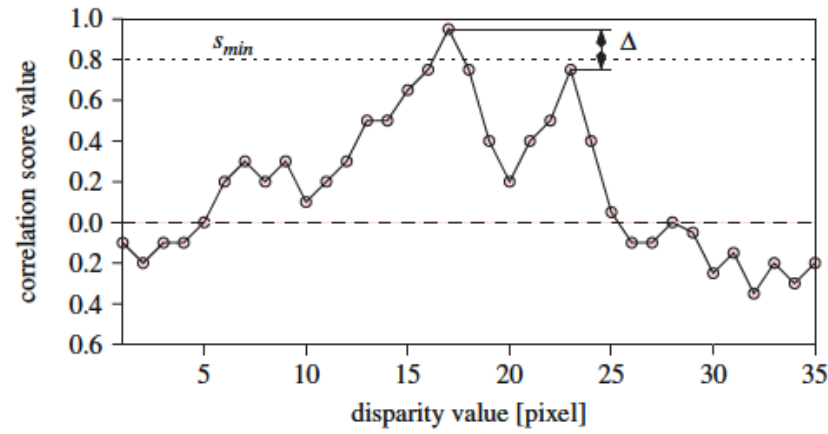

Fig. 6. Curve of correlation scores.

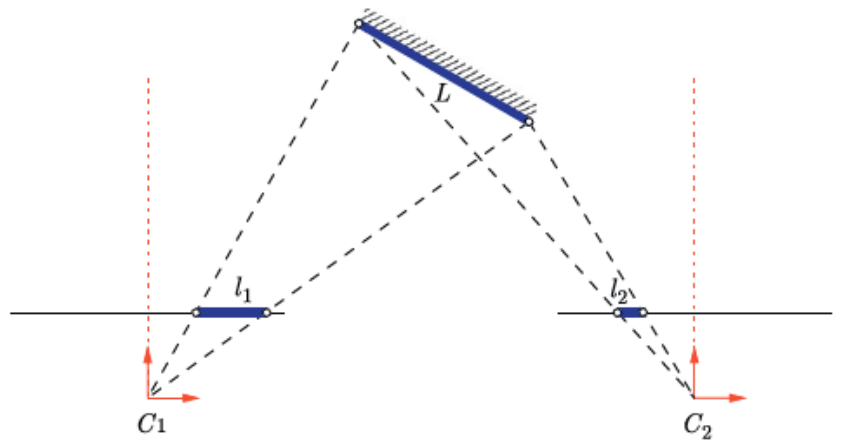

Fig. 7. Projective deformation: the segment of length $L$ in space is projected to a segment of length $l_{1}$ in the left image and to a segment of length $l_{2} \neq l_{1}$ in the right image.

within a minimum range ( $\Delta)$. By the definition, corresponding points have coordinates $(u, v)$ and $(u, v+d)$ in left and right rectified images, and $d$, the distance in pixels, is the disparity (see Fig. 5).

Fig. 5 presents a gross simplification of stereo-matching process: matching windows are assumed to be square and of the same size. In practice, due to local surface non-planarity as well as projective distortion, a square window is most likely matched with a non-square one as shown in Fig. 7. So, the correlation between the fixed left window (a rectangle) and the shifting right window (a distorted rectangle) is calculated. The optimal shape of the correlation window in the right image is computed according to the local orientation and curvature of the surface. In Fig. 6, the disparity is an integer value but in reality a subpixel correlation-based stereomatching algorithm has been developed so the disparity is a real value. For more details see $[49,53]$.

As mentioned above, it is well known that the correlation technique is efficient on textured objects. When an object does not present a suitable random, contrasted texture, one may apply a thin coating of high-contrast particles such as from spray painting [11], toner powder, ink, lithography, etc.

\subsection{3-D reconstruction}

Using the calibration parameters of each camera and the rectifying homographies, a classical triangulation method
[55] can be used to compute the 3-D position of a scene point corresponding to a stereo pair of image points (see Fig. 1), assuming that their distortion have been corrected. By repeating this operation for a large number of stereo matched pairs the 3-D shape of an object can be obtained.

\subsection{3-D displacement measurement}

Using the stereovision technique, the shape variation of an object can be measured by analyzing a sequence of pair of stereo images. Nevertheless, in experimental mechanics, we are generally interested in the surface strain field, that can be obtained by tracking the displacement of some points at the surface of an object undergoing some mechanical or thermal stress.

As already mentioned, much work has been done on 2-D displacement/strain measurement, using a single camera, on gridded objects or using correlation-based techniques. These methods can give only the in-plane strains.

The stereovision technique allows measurement of the 3-D displacement field of an object undergoing 3-D deformation.

From the pair of stereo images taken at time $t_{0}$, the 3-D shape of the object at time $t_{0}$ can be computed. From the pair of stereo images taken at time $t_{1}$, the 3-D shape of the object at time $t_{1}$ can be computed. In addition, by matching the two images taken by the left camera (or the right one) at time $t_{0}$ and $t_{1}$ (this is called temporal matching or tracking), the 3-D displacement corresponding to each image point can be computed (see Fig. 8).

The temporal matching problem is similar to the classical 2-D displacement measurement problem. It is important to note that, in this case, the epipolar constraint cannot be used since two time-varying images taken by a single camera are being dealt with. Depending on whether the object is marked with a grid or not the temporal matching problem can be tackled using feature matching techniques or a correlation-based algorithm. When 3-D displacement fields are measured by 3-D DIC, stereo-correlation (i.e. stereovision + correlation-based stereo-matching), that gives 3-D information, and pixel tracking by correlation (DIC) in the sequence of stereo images are used in conjunction. In order to achieve better accuracy an improved method (combining temporal tracking and

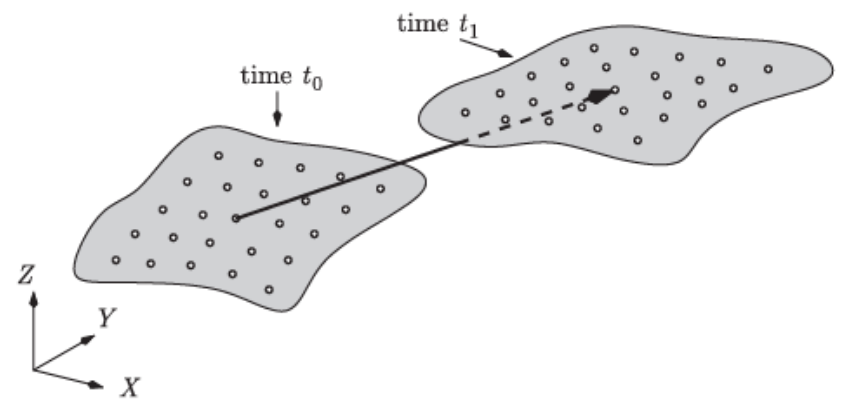

Fig. 8. 3-D displacement field computation. 
stereo-correlation) has been proposed that operates simultaneously on the two pairs of stereo images [53].

\subsection{3-D strain computation}

In [54], the strain field was computed by analyzing the initial and final configuration of an array of points marked on the surface. Each square element of the grid pattern was divided into triangular sub-elements. The principal strains in each element were determined by comparing the undeformed and deformed triangles. With 3-D DIC, no regular grid is marked on the surface of the object but the 3-D mesh resulting from the 3-D reconstruction of a Delaunay triangular mesh defined in an image can be computed (sparse reconstruction, see Fig. 9). The strain field can be computed by using each 3-D triangular element of the meshes before and after the deformation. A finiteelement software can be used for these computations. In our laboratory, the software Abaqus ${ }^{\mathrm{TM}}$ is often used for these computations. A 3-D triangular mesh is generated from the 3-D points and Abaqus ${ }^{\mathrm{TM}}$ computes the strain values from the 3-D displacements imposed at the nodes of the mesh [56].

\subsection{Accuracy}

The accuracy of 3-D reconstruction depends on many factors:

- the quality of the cameras and their resolution;

- the configuration of the two cameras (distance between the two cameras, angle between their optical axis, etc.) which governs the triangulation accuracy;

- the accuracy of the stereovision sensor calibration;

- the accuracy of the matched features in the images.

The accuracy of the matched features depends on the type of extracted feature. In [54] gridded objects were used and the grid intersection extraction accuracy was $1 / 30$ pixel. In [49] it has been shown that the DIC technique leads to an accuracy better than $1 / 100$ pixel.

Using high resolution digital cameras with $1024 \times 1024$ pixels each, the 3-D reconstruction relative accuracy in object space (the accuracy of coordinate determination

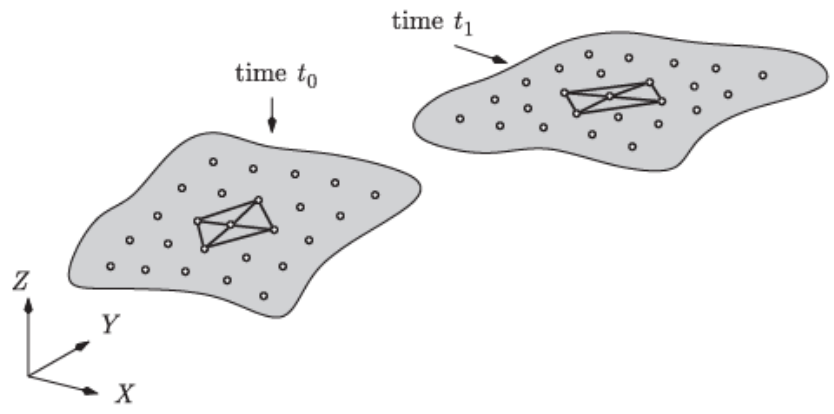

Fig. 9. 3-D strain field computation. divided by the size of the object) achieved using stereocorrelation under controlled laboratory conditions is about $1 / 50000$ (see [49] for a more detailed discussion on 3-D reconstruction accuracy).

The strains are computed by numerical derivation from the displacements measured at several points distributed over a mesh. The strain at each point of the mesh is computed using neighboring points (see Fig. 9). The accuracy of the strain computation depends on many factors: the discrete derivation scheme used (shape of the integration domain) [57], the accuracy of the displacement measurement, and the computation basis (mesh element spacing). The method proposed can reach an accuracy of $0.05 \%(500 \mu$ strain $)$ on the computed strains with triangular elements measuring 50 pixels.

For example, using the integration domain shown in Fig. 9 (four neighboring points) and the discrete derivation scheme described in [57], the uncertainty for a 2-D strain computation can be evaluated using the following relation:

$\Delta \varepsilon=\frac{\Delta d}{\sqrt{ } 2 \Delta x}$,

where $\Delta \varepsilon$ is the uncertainty on strain computation, $\Delta d$ the uncertainty on displacement measurement and $\Delta x$ the computation basis for the discrete derivation.

For example, with $\Delta d$ equal to $1 / 100$ pixel and a derivation basis $\Delta x$ equal to 14 pixels, the uncertainty on strain measurement $\Delta \varepsilon$ is equal to $0.05 \%$. An uncertainty 10 times lower $(0.005 \%)$ can be achieved by taking a derivation basis 10 times larger (140 pixels) but the result has much less local significance, which can be a problem with heterogeneous materials.

\section{Conclusion}

Stereovision (and 3-D DIC) has proven to be a powerful non-contact technique for measuring 3-D displacement/ strain fields on any 3-D object and is now widely used for industrial applications. Several commercial software are available [163-166]. The technique is very versatile and can be used for a large scale of experimental mechanics problems: it can be applied at micro or macro scale (small or large structures), it can measure both small (a few hundred of microstrains) and large strains ( $>200 \%$ ), it can be used for high-speed dynamic tests by using high-speed cameras, etc.

During the talk, ${ }^{3}$ several examples of application will be presented (sheet metal forming, polymer forming, refractory concrete or composite structures mechanical behavior characterization, bio-mechanics, high-speed impact tests, etc.). Additionally, a quite inclusive list of references on applications of stereovision (and 3-D DIC) to experimental mechanics is given at the end of this paper [58-162].

\footnotetext{
${ }^{3}$ This paper is the written support of an Invited Keynote Lecture given at the 3rd Workshop on Optical Measurement Techniques for Structures and Systems, Leuven, Belgium, 2830 May 2007.
} 


\section{References}

[1] Cloud G. Optical methods of engineering analysis. New York: Cambridge University Press; 1998.

[2] Rastogi P, editor. Photomechanics. Berlin: Springer; 1999. ISBN 3-540-65990-0.

[3] Feldmann O, Mayinger F. Optical measurements. In: Heat and mass transfer, second ed. Berlin: Springer; 2001. ISBN 978-3-540-66690-5.

[4] Molimard J, Lee JR, Surrel Y, Vautrin A. Full-field optical techniques: applications to strain measurement and mechanical identification. In: Invited keynote lecture at the 10th European conference on composite materials (ECCM10), Bruges, Belgium, 2002.

[5] Surrel Y. Full-field optical methods for mechanical engineering: essential concepts to find one's way. In: Invited keynote lecture at the second international conference on composites testing and model identification, Bristol, UK, 2004.

[6] Grédiac M. The use of full-field measurement methods in composite material characterization: interest and limitations. Composites Part A 2004;35:751 61 .

[7] Dally JW, Riley WF. Experimental stress analysis, fourth ed. College House Enterprises, LLC, Knoxville, USA, 2005. ISBN 0-9762413-0-7.

[8] Doyle J. Modern experimental stress analysis. New York: Wiley; 2004 ISBN-10: 0-470-86156-8.

[9] Sharpe J, William N, editors. Springer handbook of experimental solid mechanics. Berlin: Springer; 2007. ISBN 0-387-30877-6.

[10] Peters WH, Ranson WF. Digital imaging techniques in experimental stress analysis. Opt Eng 1982;21(3):427 31.

[11] Sutton MA, Wolters WJ, Peters WH, Ranson WF, McNeill SR. Determination of displacements using an improved digital correlation method. Image Vision Comput 1983;1(3):133 9.

[12] Chu TC, Ranson WF, Sutton MA, Peters WH. Applications of digital-image-correlation techniques to experimental mechanics. Exp Mech 1985;25(3):232 44.

[13] McNeill SR, Peters WH, Sutton MA. Estimation of stress intensity factor by digital image correlation. Eng Fract Mech 1987;28(1): 10112.

[14] Chao YJ, Sutton MA. Measurement of strains in a paper tensile specimen using computer vision and digital image correlation part 1: data acquisition and image analysis system. Tappi J 1988;70(3): 1735.

[15] Kahn-Jetter ZL, Jha NK, Bhatia H. Optimal image correlation in experimental mechanics. Opt Eng 1994;33(4):1099 105.

[16] Han G, Sutton MA, Chao YJ. A study of stationary crack-tip deformation fields in thin sheets by computer vision. Exp Mech 1994;34(2):125 40

[17] Zink AG, Davidson RW, Hanna RB. Strain measurement in wood using a digital image correlation technique. Wood Fiber Sci 1995; 27(4):346 59.

[18] Lyons JS, Liu J, Sutton MA. High-temperature deformation measurements using digital-image correlation. Exp Mech 1996; 36(1):64 70.

[19] Sun Z, Lyons JS, McNeill SR. Measuring microscopic deformations with digital image correlation. Opt Lasers Eng 1997;27(4): 40928.

[20] Choi S, Shah SP. Measurement of deformations on concrete subjected to compression using image correlation. Exp Mech 1997;37(3):307 13.

[21] Vendroux G, Knauss WG. Submicron deformation field: part 2. Improved digital image correlation. Exp Mech 1998;38(2):86 92.

[22] Sutton MA, McNeill SR, Helm JD, Chao YJ. Advances in twodimensional and three-dimensional computer vision. In: Rastogi PK, editor. Photomechanics, topics in applied physics. Berlin: Springer; 2000.

[23] Wattrisse B, Chrysochoos A, Muracciole J-M, Némoz-Gaillard M. Analysis of strain localization during tensile tests by digital image correlation. Exp Mech 2001;41(1):29 39 .
[24] Chevalier L, Calloch S, Hild F, Marco Y. Digital image correlation used to analyze the multiaxial behavior of rubber-like materials. Eur J Mech A/Solids 2001;20:169 87.

[25] Wang Y, Cuitiño AM. Full-field measurements of heterogeneous deformation patterns on polymeric foams using digital image correlation. Int J Solids Struct 2002;39(13):3777 96.

[26] Abanto-Bueno J, Lambros J. Investigation of crack growth in functionally graded materials using digital image correlation. Eng Frac Mech 2002;69(14):1695 711.

[27] Zhang D, Eggleton CD, Arola DD. Evaluating the mechanical behavior of arterial tissue using digital image correlation. Exp Mech 2002;42(4):409 16.

[28] Knauss WG, Chasiotis I, Huang Y. Mechanical measurements at the micron and nanometer scales. Mech Mater 2003;35(3):217 31.

[29] Barthelat F, Wu Z, Prorok BC, Espinosa HD. Dynamic torsion testing of nanocrystalline coatings using high-speed photography and digital image correlation. Exp Mech 2003;43(3):331 40.

[30] Li EB, Tieu AK, Yuen WYD. Application of digital image correlation technique to dynamic measurement of the velocity field in the deformation zone in cold rolling. Opt Lasers Eng 2003; 39(4):479 88.

[31] Zhang J, Xiong C, Li H, Li M, Wang J, Fang J. Damage and fracture evaluation of granular composite materials by digital image correlation method. Acta Mech Sin 2004;20(4):408 17.

[32] Parsons E, Boyce MC, Parks DM. An experimental investigation of the large-strain tensile behavior of neat and rubber-toughened polycarbonate. Polymer 2004;45:2665 84.

[33] Bergonnier S, Hild F, Roux S. Digital image correlation used for mechanical tests on crimped glass wool samples. J Strain Anal Eng Des 2005;40(2):185 97.

[34] Ambu R, Aymerich F, Bertolino F. Investigation of the effect of damage on the strength of notched composite laminates by digital image correlation. J Strain Anal Eng Des 2005;40(5):451 62.

[35] Chang S, Wang CS, Xiong CY, Fang J. Nanoscale in-plane displacement evaluation by AFM scanning and digital image correlation processing. Nanotechnology 2005;16(4):344 9.

[36] Jin H, Bruck HA. A new method for characterizing nonlinearity in scanning probe microscopes using digital image correlation. Nanotechnology 2005;16(9):1849 55.

[37] Yoneyama S, Morimoto Y, Takashi M. Automatic evaluation of mixed-mode stress intensity factors utilizing digital image correlation. Strain 2006;42(1):21 9.

[38] Hild F, Roux S. Digital image correlation: from displacement measurement to identification of elastic properties a review. Strain 2006;42(2):69 80 .

[39] Ait-Amokhtar H, Vacher P, Boudrahem S. Kinematics fields and spatial activity of Portevin-Le Châtelier bands using the digital image correlation method. Acta Mater 2006;54(16):4365 71.

[40] Boyce BL, Reu PL, Robino CV. The constitutive behavior of laser welds in $304 \mathrm{~L}$ stainless steel determined by digital image correlation. Metall Mater Trans A 2006;37(8):2481 92.

[41] Yaofeng S, Pang JHL. AFM image reconstruction for deformation measurements by digital image correlation. Nanotechnology 2006;17(4):933 9.

[42] Berfield TA, Patel JK, Shimmin RG, Braun PV, Lambros J, Sottos NR. Micro- and nanoscale deformation measurement of surface and internal planes via digital image correlation. Exp Mech 2007;47(1): 5162.

[43] Fayolle X, Calloch S, Hild F. Controlling testing machines with digital image correlation. Exp Tech 2007;31(3):57 63 .

[44] Li X, Xu W, Sutton MA, Mello M. In situ nanoscale in-plane deformation studies of ultrathin polymeric films during tensile deformation using atomic force microscopy and digital image correlation techniques. IEEE Trans Nanotechnology 2007;6(1): 412.

[45] Yoneyama S, Kitagawa A, Iwata S, Tani K, Kikuta H. Bridge deflection measurement using digital image correlation. Exp Tech 2007;31(1):34 40 . 
[46] Salvi J, Armangué X, Battle J. A comparative review of camera calibrating methods with accuracy evaluation. Pattern Recognition 2002;35:1617 35 .

[47] Triggs B, McLauchlan P, Hartley R, Fitzgibbon A. Bundle adjustment a modern synthesis. In: Triggs B, Zisserman A, Szeliski R, editors. Vision algorithms. Berlin: Springer; 2000.

[48] Garcia D, Orteu J-J, Devy M. Accurate calibration of a stereovision sensor: comparison of different approaches. In: Proceedings of vision, modeling, and visualization 2000, Saarbrücken, Germany, 2000 .

[49] Garcia D. Mesure de formes et de champs de déplacements tridimensionnels par stéréo-corrélation d'images, $\mathrm{PhD}$ thesis, Institut National Polytechnique de Toulouse, France; December 2001

[50] Ayache N, Hansen C. Rectification of images for binocular and trinocular stereovision. In: Proceedings of ninth IEEE international conference on pattern recognition, Roma, Italy, 1988, p. 116.

[51] Loop C, Zhang Z. Computing rectifying homographies for stereo vision. Technical Report, Microsoft Research MSR-TR-99-21; 1999.

[52] Faugeras OD. Three-dimensional computer vision: a geometric viewpoint. Cambridge, MA: The MIT Press; 1993.

[53] Garcia D, Orteu J-J, Penazzi L. A combined temporal tracking and stereo-correlation technique for accurate measurement of $3 \mathrm{D}$ displacements: application to sheet metal forming. J Mat Process Technol 2002;125 126:736 42.

[54] Orteu J-J, Garric V, Devy M. Camera calibration for 3D reconstruction: application to the measure of $3 \mathrm{D}$ deformations on sheet metal parts. In: SPIE proceedings of European symposium on lasers, optics and vision in manufacturing (EUROPTO), vol. 3101, Munich, Germany, 1997.

[55] Hartley R, Sturm P. Triangulation. Comput Vision Image Understanding 1997;68(2):146 57.

[56] Cornille N. Accurate 3D shape and displacement measurement using a scanning electron microscope. $\mathrm{PhD}$ thesis, INSA, France and University of South Carolina, Columbia, USA; June 2005.

[57] Allais L, Bornert M, Bretheau T, Caldemaison D. Experimental characterization of the local strain field in a heterogeneous elastoplastic material. Acta Metall Mater 1994;42(11):3865 80.

\section{References on applications of stereovision and 3-D DIC to experimental mechanics}

[58] Ackermann F. Digital image correlation: performance and potential application in photogrammetry. Photogramm Rec 1984;11(64): 42939.

[59] Albertani R, Stanford B. Hubner JP, Ifju PG. Aerodynamic coefficients and deformation measurements on flexible micro air vehicle wings. Exp Mech 2007;47(5):625 35.

[60] Alpers B, Bergmann D, Galanulis K, Winter D. Advanced deformation measurement in sheet metal forming. In: Proceedings of sixth international conference on technology of plasticity, Nuremberg, Germany, 1999.

[61] Andresen K. Strain tensor for large three-dimensional surface deformation of sheet metal from an object grating. Exp Mech 1999;39(1):30 5.

[62] Becker T, Splitthof K, Siebert T, Kletting P. Error estimations of digital image correlation measurements. In: Slangen P, Cerruti C, editors. SPIE proceedings of speckle06 conference, vol. 6341, Nîmes, France, 2006

[63] Berthaud Y, Torrenti JM, Fond C. Analysis of localization in brittle materials through optical techniques. Exp Mech 1997;37(2):216 20.

[64] Berube KA, Lopez-Anido RA, Caccese V. Variability in flexural response of E-Glass/vinyl ester composites fabricated using the VARTM process. In: Proceedings of SAMPE 2006, Long Beach, CA, USA, 2006.
[65] Boochs F. Off-line compilation of photogrammetric stereo models using digital image correlation. Photogrammetria 1987;41(3): 18399.

[66] Bruck HA, Schreier HW, Sutton MA, Chao YJ, Deng X, Davoud M. Distortion in GMAW of thin plates: temperature and 3-D deformation measurements using high-speed thermal imaging and stereoscopic video imaging. In: Proceedings of fifth international conference on trends in welding research, Pine Mountain, GA, USA, 1998, p. 96771.

[67] Burguete R. Keynote presentation: industrial applications of high speed 3-D DIC to structural tests. In: Proceedings of SEM 2007 annual conference on experimental and applied mechanics, Springfield, MA, USA, 2007.

[68] Cárdenas-Garcia JF, Yao HG, Zheng S. 3D reconstruction of objects using stereo imaging. Opt Lasers in Eng 1995;22(3):193 213.

[69] Choi S, Shah SP. Measurement of deformations on concrete subjected to compression using image correlation. Exp Mech 1997;37(3):307 13

[70] Compston P, Styles M, Kalyanasundaram S. Low energy impact damage modes in aluminum foam and polymer foam sandwich structures. J Sandwich Struct Mater 2006;8(5):365 79.

[71] Cornille N, Garcia D, Sutton MA, McNeill SR, Orteu J-J. Automated 3-D reconstruction using a scanning electron microscope. In: Proceedings of SEM 2003 annual conference on experimental and applied mechanics, Charlotte, North Carolina, USA, 2003.

[72] Cornille N, Garcia D, Sutton MA, McNeill SR, Orteu J-J. 3D shape and strain measurements using a scanning electron microscope. In: Proceedings of international conference on experimental mechanics (ICEM12), Bari, Italy, 2004.

[73] Cornille N. Accurate 3D shape and displacement measurement using a scanning electron microscope. PhD thesis, INSA, France and University of South Carolina, Columbia, USA; June 2005.

[74] Davies PA, Randle V. Combined application of electron backscatter diffraction and stereo-photogrammetry in fractography studies. J Microsc 2001;204(1):29 38.

[75] Florando JN, Rhee M, Arsenlis A, LeBlanc MM, Lassila DH. Calculation of the slip system activity in deformed zinc single crystals using digital 3-D image correlation data. Philos Mag Lett 2006;86(12):795 805

[76] Fournier N. Image stereo-correlation for the fast analysis of damages on aircrafts. In: Proceedings of SEM 2007 annual conference on experimental and applied mechanics, Springfield, MA, USA, 2007.

[77] Galanulis K, Hofmann A. Determination of forming limit diagrams using an optical measurement system. In: Proceedings of seventh international conference on sheet metal SheMet'99, Erlangen, Germany, 1999.

[78] Garcia D, Orteu J-J. 3D deformation measurement using stereocorrelation applied to the forming of metal or elastomer sheets. In: Proceedings of international workshop on video-controlled materials testing and in situ microstructural characterization, Nancy, France, 1999.

[79] Garcia D, Orteu J-J. 3D Deformation measurement using stereocorrelation applied to experimental mechanics. In: Proceedings of 10th FIG international symposium on deformation measurements, Orange, CA, USA, 2001

[80] Garcia D. Mesure de formes et de champs de déplacements tridimensionnels par stéréo-corrélation d'images. $\mathrm{PhD}$ thesis, Institut National Polytechnique de Toulouse, France, December 2001.

[81] Garcia D, Orteu J-J, Cutard T, Cailleux E. Application of stereovision to the mechanical characterization of refractory ceramics reinforced with metallic fibers. In: Proceedings of SEM 2002 annual conference on experimental and applied mechanics, Milwaukee, WI, USA, 2002.

[82] Garcia D, Orteu J-J, Penazzi L. A combined temporal tracking and stereo-correlation technique for accurate measurement of $3 \mathrm{D}$ 
displacements: application to sheet metal forming. J Mater Process Technol 2002;125 126:736 42 .

[83] He X, Jiang M. 3D information acquired by the correlation of projected fringe patterns. In: Quan C, Chau FS, Asundi A, Wong BS, Lim CT, editors. SPIE proceedings of third international conference on experimental mechanics and third conference of the Asian committee on experimental mechanics, vol. 5852. Singapore, 2005. p. 25763 .

[84] Helava UV. Digital correlation in photogrammetric instruments. Photogrammetria 1978;34(1):18 41.

[85] Helm JD, McNeill SR, Sutton MA. Improved three-dimensional image correlation for surface displacement measurement. Opt Eng 1996;35(7):1911 20.

[86] Helm JD, Sutton MA, Boone ML. Characterizing crack growth in thin aluminum panels under tension torsion loading using threedimensional digital image correlation. In: Lucas GF, McKeighan PC, Ransom JS, editors. Nontraditional methods of sensing stress, strain, and damage in materials and structures: second volume, ASTM STP 1323. American Society for Testing and Materials; 2001.

[87] Helm JD, Sutton MA, McNeill SR. Deformations in wide, centernotched, thin panels, part I: three-dimensional shape and deformation measurements by computer vision. Opt Eng 2003;42(5): 1293305.

[88] Helm JD, Sutton MA, McNeill SR. Deformations in wide, centernotched, thin panels, part II: finite element analysis and comparison to experimental measurements. Opt Eng 2003;42(5):1306 20.

[89] Hemmleb H, Schubert M. Digital microphotogrammetry determination of the topography of microstructures by scanning electron microscope. In: Proceedings of second Turkish German joint geodetic days, Berlin, Germany, 1997. p. 74552.

[90] Herbst C, Splitthof K, Ettemeyer A. New features in digital image correlation techniques. In: Proceedings of society of automotive engineers (SAE) world congress SAE technical paper in SP-1957, Detroit, MI, USA, 2005.

[91] Hijazi A, Yardi N, Madhavan V. Determination of forming limit curves using 3D digital image correlation and in situ observation. In: Proceedings of SAMPE 2004, Long Beach, CA, USA, 2004.

[92] Holstein D, Salbut L, Kujawinska M, Jüptner W. Hybrid experimental-numerical concept of residual stress analysis in laser weldments. Exp Mech 2001;41(4):343 50.

[93] Huang YH, Quan C, Tay CJ, Chen LJ. Shape measurement by the use of digital image correlation. Opt Eng 2005;44(8):087011.

[94] Jacobsson L, Enqvist B. Deformation measurement on rock specimen during Brazilian test using white light speckle photography. Technical Report 2004:38, SP Swedish National Testing and Research Institute; 2004

[95] Janova D, Jan J. Robust surface reconstruction from stereo SEM images. In: Hlavac V, Sara R, editors. Computer analysis of images and patterns. Berlin: Springer; 1995.

[96] Jones A, Shaw J, WA. An experimental facility to measure the chemorheological response of inflated elastomer membranes at high temperature. Exp Mech 2006;46(5):579 87.

[97] Kahn-Jetter ZL, Chu TC. Three-dimensional displacement measurements using digital image correlation and photogrammic analysis. Exp Mech 1990;30(1):10 6.

[98] Kim D-H, Lee J-H, Kang K-J. An experimental method to measure Q-parameter for two parameter theory of ductile fracture. In: Proceedings of ASME international mechanical engineering congress, Washington, DC, USA, 2003.

[99] Kolednik O, Stüwe HP. The stereophotogrammetric determination of the critical crack tip opening displacement. Eng Fract Mech 1985;21(1):145 55 .

[100] Lacey AJ, Thacker NA, Crossley S, Yates RB. A multi-stage approach to the dense estimation of disparity from stereo SEM images. Image Vision Comput 1998;16(1):373 83.

[101] Langerak N, Atzema E, Essing J. Strain measurements with the PHAST system. In: International Deep Drawing Research Group
(IDDRG'2000) meeting of the working groups, Ann Arbor, MI, USA, 2000.

[102] Larsson L, Sjödahl M, Thuvander F. Microscopic 3-D displacement field measurements using digital speckle photography. Opt Lasers Eng 2004;41(5):767 77.

[103] Lawler JS, Keane DT, Shah SP. Measuring three-dimensional damage in concrete under compression. ACI Mater J 2001;98: 46575.

[104] Lecompte D, Vantomme J, Sol H. Crack detection in a concrete beam using two different camera techniques. Struct Health Monit 2006;5(1):59 68

[105] Lee J-H, Kang K-J. In situ measurement of lateral side-necking of a fracture specimen using a stereo vision and digital image correlation. J Korean Soc Precis Eng 2004;21(10):154 61.

[106] Lockwood WD, Reynolds AP. Use and verification of digital image correlation for automated 3-D surface characterization in the scanning electron microscope. Mater Charact 1999;42(2): 12334.

[107] Lopez-Anido R, El-Chiti FW, Muszyñski L, Dagher HJ, Thompson LD, Hess PE. Composite material testing using a 3-D digital image correlation system. In: Proceedings of composites 2004 conference, Tampa, FL, USA, 2004.

[108] Luo P-F. Measurement of three-dimensional crack tip deformation by digital image processing. $\mathrm{PhD}$ thesis, South Carolina University, Columbia, USA; 1992.

[109] Luo PF, Chao YJ, Sutton MA, Peters WH. Accurate measurement of three-dimensional deformations in deformable and rigid bodies using computer vision. Exp Mech 1993;33(2):123 32.

[110] Luo PF, Chao YJ, Sutton MA. Application of stereo vision to threedimensional deformation analyses in fracture experiments. Opt Eng 1994;33(3):981 90.

[111] Luo PF, Liou SS. Measurement of curved surface by stereo vision and error analysis. Opt Eng 1998;30(6):471 86.

[112] Luo PF, Huang FC. Application of stereo vision to the study of mixed-mode crack-tip deformations. Opt Lasers Eng 2000;33(5): 34968.

[113] Luo PF, Chen JN. Measurement of curved-surface deformation in cylindrical coordinates. Exp Mech 2000;40(4):345 50.

[114] McGinnis MJ, Pessiki S, Turker H. Application of three-dimensional digital image correlation to the core-drilling method. Exp Mech 2005;45(4):359 67.

[115] McGinnis MJ, Pessiki S. Influence of steel reinforcement on in-situ stress evaluation in concrete structures by the core-drilling method. In: Proceedings of the quantitative nondestructive evaluation conference, vol. 820. American Institut of Physics (AIP); 2006. p. 135865 .

[116] McGowan DM, Ambur DR, Hanna TG, McNeill SR. Evaluating the compressive response of notched composite panels using fullfield displacements. J Aircr 2001;38(1):122 9.

[117] Medina-Cetina Z, Rechenmacher A, Image-based sensing of 3-D displacements for enhanced soil model calibration. In: DeGroot DJ, DeJong JT, Frost JD, Baise LG, editors. Proceedings of GeoCongress 2006, Atlanta, GA, USA, 2006.

[118] Miller TJ, Schreier HW, Reu PL. High-speed DIC data analysis from a shaking camera system. In: Proceedings of SEM 2007 annual conference on experimental and applied mechanics, Springfield, MA, USA, 2007.

[119] Montemayor E, Ray RP. Displacement measurements for cyclic triaxial tests using digital image correlation. In: Proceedings of GeoFrontiers 2005 congress, Austin, TX, USA, 2005.

[120] Morimoto Y, Fujigaki M. Automated analysis of 3-D shape and surface strain distributions of a moving object using stereo vision. Opt Lasers Eng 1993;18(3):195 212.

[121] Moser R, Lightner JG. Using three-dimensional digital imaging correlation techniques to validate tire finite-element model. Exp Tech 2007;31(4):29 36 .

[122] Nam TH, Marvalová B. Three-dimensional displacement measurement of inflated air-spring shell using stereo-correlation technique. 
In: Proceedings of 42nd international conference of experimental stress analysis (EAN), Kasperské Hory, Czech Republic, 2004.

[123] Nam TH. Mechanical properties of the composite material with elastomeric matrix reinforced by textile cords. PhD thesis, Technical University of Liberec, Czech Republic; 2004.

[124] Nelson DV, Makino A, Schmidt T. Residual stress determination using hole drilling and 3D image correlation. Exp Mech 2006;46(1): 318.

[125] Nicolella DP, Nicholls AE, Lankford J, Davy DT. Machine vision photogrammetry: a technique for measurement of microstructural strain in cortical bone. J Biomechanics 2001;34(1):135 9.

[126] Orteu J-J, Garric V, Devy M. Camera calibration for 3D reconstruction: application to the measure of $3 \mathrm{D}$ deformations on sheet metal parts. In: SPIE proceedings of European symposium on lasers, optics and vision in manufacturing (EUROPTO), vol. 3101, Munich, Germany, 1997

[127] Orteu J-J, Cutard T, Garcia D, Cailleux E, Robert L. Application of stereovision to the mechanical characterisation of ceramic refractories reinforced with metallic fibres. Strain 2007;43(2):96 108

[128] Rechenmacher AL, Medina-Cetina Z. Digital-imaging based measurement of deformed shapes of axisymmetric soil specimens. In: Proceedings of 16th ASCE engineering mechanics conference, Seattle, WA, USA, 2003.

[129] Rechenmacher AL. Imaging-based experimental soil mechanics. In: Yamamuro JA, Koseki J, editors. Geomechanics: testing, modeling, and simulation. American Society of Civil Engineers (ASCE); 2005.

[130] Revilock DM, Thesken JC, Schmidt TE. 3D digital image correlation of a composite overwrapped pressure vessel during hydrostatic pressure tests. In: Proceedings of SEM 2007 annual conference on experimental and applied mechanics, Springfield, MA, USA, 2007.

[131] Richards RG, Wieland M, Textor M. Advantages of stereo imaging of metallic surfaces with low voltage backscattered electrons in a field emission scanning electron microscope. J Microsc 2000;199(2):115 23.

[132] Robert L, Nazaret F, Cutard T, Orteu J-J. Use of 3-D digital image correlation to characterize the mechanical behavior of a fiber reinforced refractory castable. Exp Mech 2007;47(6):761 73.

[133] Rotrou Y, Sentenac T, Robert L, Orteu J-J. An innovative method for 3D shape/displacement/strain and temperature measurement using a single sensor. In: Proceedings of photomechanics 2006, Clermont-Ferrand, France, 2006

[134] Schmidt TE, Tyson J, Galanulis K. Full-field dynamic displacement and strain measurement using advanced 3D image correlation photogrammetry: part I. Exp Tech 2003;27(3):47 50 .

[135] Schmidt TE, Tyson J, Galanulis K. Full-field dynamic displacement and strain measurement specific examples using advanced 3D image correlation photogrammetry: part II. Exp Tech 2003;27(4): 226.

[136] Schmidt TE, Tyson J, Revilock DM, Padula S, Pereira JM, Melis $\mathrm{M}$, et al. Performance verification of $3 \mathrm{D}$ image correlation using digital high-speed cameras. In: Proceedings of SEM 2005 annual conference on experimental and applied mechanics, Portland, OR, USA, 2005.

[137] Schreier HW. Investigation of two and three-dimensional image correlation methods with applications in mechanical engineering. $\mathrm{PhD}$ thesis, University of South Carolina, Columbia, USA; September 2003.

[138] Schreier HW, Garcia D, Sutton MA. Advances in light microscope stereo vision. Exp Mech 2004;44(3):278 88 .

[139] Siebert T, Becker T, Splitthof K. High speed digital image correlation techniques. In: Proceedings of society of automotive engineers (SAE) world congress SAE technical paper in SP-2033, Detroit, MI, USA, 2006

[140] Siebert T, Becker T, Spiltthof K, Neumann I, Krupka R. Highspeed digital image correlation: error estimations and applications. Opt Eng 2007;46(5):051004. (7pp).
[141] Splitthof K, Stecklum S. 3D digital image correlation. VDI-Berichte 2004;1844:209 16

[142] Stanford B, Albertani R, Ifju P. Static finite element validation of a flexible micro air vehicle. Exp Mech 2007;47(2):283 94.

[143] Sutton MA, Turner JL, Chao YJ, Bruck HA, Chae TL. Experimental investigations of three-dimensional effects near a crack tip using computer vision. Int J Frac 1992;53(3):201 28.

[144] Sutton MA, McNeill SR, Helm JD, Boone ML. Measurement of crack tip opening displacement and full-field deformations during fracture of aerospace materials using $2 \mathrm{D}$ and $3 \mathrm{D}$ image correlation methods. In: Lagarde A, editor. IUTAM symposium on advanced optical methods and applications in solid mechanics. Solid mechanics and its applications, vol. 82. Netherlands: Springer; 1998. p. 57180.

[145] Sutton MA, McNeill SR, Helm JD, Chao YJ. Advances in twodimensional and three-dimensional computer vision. In: Rastogi PK, editor. Photomechanics, Topics in applied physics. Berlin: Springer; 2000.

[146] Sutton MA, Yan J, Deng X, Cheng C-S, Zavattieri P. Threedimensional digital image correlation to quantify deformation and crack-opening displacement in ductile aluminum under mixed-mode I/III loading. Opt Eng 2007;46(5):051003. (17pp).

[147] Synnergren P. Measurement of three-dimensional displacement fields and shape using electronic speckle photography. Opt Eng 1997;36(8):2302 10.

[148] Synnergren P. Stereovision setup for accurate 3D deformation measurements. In: Yamaguchi I, editor. SPIE proceedings of optical engineering for sensing and nanotechnology, vol. 3740, Yokohama, Japan, 1999. p. 747.

[149] Synnergren P, Sjödahl M. A stereoscopic digital speckle photography system for 3-D displacement field measurements. Opt Lasers Eng 1999;31(6):425 43.

[150] Synnergren P, Goldrein HT. Dynamic measurements of internal three-dimensional displacement fields with digital speckle photography and flash X rays. Appl Opt 1999;38(28):5956 61.

[151] Synnergren P. White light and X-ray digital speckle photography. PhD thesis, Luleå University of Technology, Sweden; 2000.

[152] Synnergren P, Berglund T, Söderkvist I. Estimation of curl in paper using a combination of shape measurement and least-squares modelling. Opt Lasers Eng 2001;35(2):105 20.

[153] Tiwari V, Sutton MA, McNeill SR. Assessment of high speed imaging systems for 2D and 3D deformation measurements: methodology development and validation. Exp Mech 2007;47(4): 56179.

[154] Tong W. Plastic surface strain mapping of bent sheets by image correlation. Exp Mech 2004;44(5):502 11.

[155] Tyson J, Schmidt T, Galanulis K. Advanced photogrammetry for robust deformation and strain measurement, In: Proceedings of SEM 2002 annual conference on experimental and applied mechanics, Milwaukee, WI, USA, 2002.

[156] Tyson J, Schmidt T, Galanulis K. Biomechanics deformation and strain measurements with 3D image correlation photogrammetry. Exp Tech 2002;26(5):39 42.

[157] Vialettes P, Siguier J-M, Guigue P, Karama M, Mistou S, Dalverny $\mathrm{O}$, et al. Visco-elastic laws study for mechanical modelization of super-pressure balloons. In: Proceedings of AIAA fifth aviation, technology, integration, and operations (ATIO) and 16th lighterthan-air systems technology and balloon systems conferences, Arlington, VA, USA, 2005.

[158] Vialettes P, Siguier J-M, Guigue P, Karama M, Mistou S, Dalverny $\mathrm{O}$, et al. Experimental and numerical simulation of super-pressure balloon apex section: mechanical behavior in realistic flight conditions. Adv Space Res 2006;37(11):2082 6.

[159] Vignon F, Le Besnerais G, Boivin D, Pouchou J-L, Quan L. 3D reconstruction from scanning electron microscopy using stereovision and self-calibration. In: Proceedings of physics in signal and image processing, Marseille, France, 2001. 
[160] Vogel JH, Lee D. An automated two-view method for determining strain distributions on deformed surfaces. J Mater Shaping Technol 1989;6(4):205 16.

[161] Walz T, Ettemeyer A. Material and component validation by speckle interferometry and correlation methods. Insight NonDestructive Testing Condition Monitoring 2005;47(4):226 31 .

[162] Wasil A, Merchant DC. Plate-deflection measurement by photogrammetric methods. Exp Mech 1964;4(3):77 83.

\section{Commercial software}

[163] Vic-3D commercial software. Correlated Solutions Incorporated. 〈http://www.correlatedsolutions.com/〉.

[164] ARAMIS commercial software. GOM, 〈http://www.gom.com/〉.

[165] StrainMaster commercial software. LaVision, 〈http://www.lavision.de/ $/$.

[166] Q-400 commercial software. Dantec Dynamics. 〈http://www. dantecdynamics.com/>. 